\title{
Research on Social Work Action of Rural Elderly Volunteers Cultivation
}

\author{
Zhang Rongyan ${ }^{1, \mathrm{a}}$, Xiu Ning ${ }^{2, \mathrm{~b}}$ \\ ${ }^{1}$ Changchun University of Science and Technology School of Law, China \\ ${ }^{2}$ Changchun University of Science and Technology School of Law, China \\ a1043593636@qq.com, ${ }^{b} 1436541928 @ q q . c o m$
}

\begin{abstract}
Due to the aging of the population and the acceleration of the urbanization process, most of our country's rural areas have entered the aging stage, and the proportion of the elderly population is increasing. Therefore, the cultivation of rural volunteers, especially the elderly volunteers, is a key step for rural communities to carry out voluntary service. This article will take the elderly in village $\mathrm{X}$, Changling county, Jilin province as the research object, to make full use of the special features of the local elderly and explore their potential. The article will use the method of action research, let the elderly and social workers formulate and implement the plan together, explore the path for social workers to train rural elderly volunteers. We can fill in the vacancy of local volunteer service resources, reduce the dependence on foreign volunteers. On the one hand, the elderly can better realize their own values. On the other hand, they can actively deal with the aging rural areas.
\end{abstract}

Keywords: rural elderly volunteers, action research, cultivate

\section{INTRODUCTION}

China's natural population growth rate is declining year by year, the number of people aged 65 and above is increasing sharply, the old-age dependency rate is rising sharply, and the trend of aging is accelerating obviously. At the same time, due to the rapid urbanization process, the gap between urban and rural areas is widening again, resulting in the current situation of brain drain and rural aging, and the demand for pension services is becoming more and more intense. However, due to the poor rural infrastructure, the fewer professional organizations, and insufficient ability of the elderly, the way and channel to participate in voluntary activities are single, which is difficult to meet the diversified needs for pension services [1].

Therefore, the purpose of this study is to give full play to the professional advantages of social workers, use social work methods, take rural communities as a platform, and integrate research, education and practice [2], through action research methods, to explore the professional path for social workers to cultivate rural elderly volunteers, to help establish a team of elderly volunteers, to teach them volunteer service knowledge and skills to let them play their role in team building, and to explore and practice the "four-club linkage" mechanism in rural areas. It is of great significance for the elderly to improve their knowledge level, give full play to their own values, coordinate interpersonal relationships, further build a rural old-age service system and build a new socialist countryside.

\section{RESEARCH METHODS AND RELATED THEORIES}

\subsection{Action Research Methodology}

Action research advocates a combination of research and action. Researchers should conduct active research on the actions taken by individuals in their social position, social status, and the formal economic structure of society, as well as the impact of the actions taken. Rural elderly volunteers, as actors, and social workers, as researchers, should acquire and create knowledge together. Through participatory research, local people contribute to their parts in defining problems, researching steps, formulating steps, action plans and results evaluation, finding problems in the development of the community, and formulating intervention programs and practical actions to better serve for local residents [2].

\subsection{Relevant Theories}

This research mainly involves three theories. The first is the theory of dominant perspective. This theory was put forward by Dennis Saleebey, a professor of the School of Social Welfare at the University of Kansas in the United States, in his book "Advantage Perspective: A New Model of Social Work Practice". The theory focuses on one's inner strength and dominant resources. Social workers use this view to explore the inner potential and advantages of the rural elderly and help them cope with life. The second 
is empowerment. Webster's New World Dictionary (1982) defines empowerment as "empowerment or authority". Empowerment; Enable; Allow ". This is an intervention method and action to expand individuals or groups and to identify and stimulate the potential of the case owners. Empowerment is a process [3], through which people become strong enough to participate in events and institutions that affect their lives, share under the control of these events and institutions, and strive to change them. Social workers empower the rural elderly, stimulate their potential, exert their own strength in the community and society, and stabilize the power structure. The third is the theory of sustained activity for the elderly, which pays more attention to the individual differences among the elderly, and believes that the sustained pattern of individual behaviour is more suitable for the elderly in rural areas to enter new social roles, choose the appropriate way of life, and obtain the feeling of happiness. In this way, they can also make themselves gain in old age [4].

\section{ACTION REAEARCH AND SOCIAL WORK INTERVENTION}

\subsection{Problem Definition}

This article mainly takes the senior citizens of village $\mathrm{X}$ in Jilin province as the research object. There are 600 old people in village $\mathrm{X}, 342$ of whom are aged 60-69, accounting for 57\%; There are 187 middle-aged people aged $70-79$, accounting for $31.17 \%$; There are 71 senior citizens aged 80 and above, accounting for $11.83 \%$.

Table 1 Percentage of elderly people of all ages in village $\mathrm{X}$

\begin{tabular}{c|c|c}
\hline & Frequency & Percentage \\
\hline $60-69$ & 342 & 57.00 \\
$70-79$ & 187 & 31.17 \\
80 and above & 71 & 11.83 \\
Total & 600 & 100.00 \\
\hline
\end{tabular}

The proportion of young elderly is relatively large, but there are very few elderly volunteers, the development of voluntary activities is slow, the voluntary consciousness is not strong, and the elderly group as an important resource in the community governance group, has not yet been fully utilized. The main reason is that the elderly lack the awareness of voluntary service, and their ability to accept new things is relatively slow. The implementation of voluntary service actions by the elderly is far from enough. Therefore, the level of participation is low, and even if one wishes, who does not know how to volunteer. The ability and level of volunteer service need to be improved. So, social workers focus on the cultivation of rural elderly volunteers, dig into the potential of the elderly themselves, improve the service ability and level of elderly volunteers, and strengthen the contact between the elderly, so that the elderly can actively respond to aging.

\subsection{Promoting Action Plans}

\subsubsection{Recruiting volunteers}

Recruiting volunteers is a prerequisite for voluntary activities to be carried out. On the one hand, it can enrich the life of the elderly in rural areas and enable them to lead a full and meaningful life in their later years. On the other hand, the selection of the rural elderly as the research object is based on Maslow's hierarchy of needs theory. The elderly helping others is a need of self-realization, when they help others, they can obtain a sense of satisfaction at the same time [5]. The preparatory work for the recruitment is mainly to cooperate with local village committee members and social workers, communicate and exchange, and to obtain the support of the local government. As the leader, village secretary was the first to join the volunteer team. Members of the village Committee also responded positively to the call and joined the volunteer team one after another. They helped recommend influential old people and called on everyone to join the volunteer activities. With the help of We Chat platform, advertisements posted in communities and neighbourhood committee recommendations, volunteers are widely recruited to promote volunteer service activities. Widely recruiting the elderly who are interested in volunteer activities, actively recommending the elderly with volunteer experience, letting them be the backbone of the rural elderly volunteer team, and teaching other volunteer experiences. Inviting the elderly with a certain social status and knowledge reserve can call on local residents to come together to do great things. Through communication with the applicants, we know their service wishes, service experiences, physical fitness and other personal conditions. Through the final selection, a total of 20 elderly people joined the voluntary activities. Some of them took part in this kind of helping activities for the first time, full of curiosity and enthusiasm. Some of them had been volunteers, hoping to transfer their experience to others. Social workers lead rural elderly volunteers to actively participate in this public welfare activity in a professional spirit to promote community and even social stability.

\subsubsection{Volunteer Cultivation}

Cultivation methods mainly include classroom teaching and cultivation in project activities [2]. The main content of classroom teaching is to understand what volunteers and volunteer spirit are, what abilities and skills volunteers should have in the process of service, and what kind of service consciousness they should have. The cultivation of project activities takes the project as the main carrier. Elderly volunteers improve their service level and their service ability in the process of activities. At the same time, they will also find their own shortcomings. Social workers should communicate with 
volunteers in a timely manner and adjust the service plan in a timely manner.

\subsubsection{Social workers help rural elderly volunteers explore their potential.}

Everyone has some potential that he has not developed. We mainly adopt the way of classroom teaching, not the traditional learning mode, but through an experiential group activity. The themes of the group activities are respectively: An ice-breaking trip; Finding your own advantages and disadvantages; Finding self-confidence and enhancing self-confidence; Improving interpersonal relationships; Breaking through the limitation of thinking. Through these group interactions, the social workers let the members get to know each other. As the host and the participants of the activity, the social workers got close contact with the elderly volunteers, captured their characteristics, stimulated some people's communication and expression ability; saw some people's rational and calm side, and the warm side of caring for others. At the same time, the advantages of volunteers were exploited, and they were given the opportunity to act independently. Social workers gave full play to the role of leaders and helpers, allowed the elderly to fully feel their own value in the process of group activities, broke through limitations, enhanced self-confidence and improved interpersonal relationships.

\subsubsection{Social workers assist rural elderly volunteers in voluntary activities.}

To an acceptable extent to the elderly volunteers in village $\mathrm{X}$, social workers taught them certain professional knowledge and skills through project training to enhance the volunteer ability of the elderly volunteers in village $\mathrm{X}$. First of all, social workers and elderly volunteers had jointly established a training system for rural elderly volunteers. The training content combined the local actual situation in Village $\mathrm{X}$ and made full use of local resources, which met the training needs of rural elderly volunteers. Secondly, a performance evaluation system had been established to promote the learning growth of elderly volunteers. At this stage, many projects had been carried out: the harmonious creation of regional civilization----volunteers were divided into two groups, one was civilization supervisor and the other was voluntary propagandist. Volunteers supervised everyone to travel in a civilized way, sorted out the vehicles parked randomly, carefully cleaned up the garbage on the streets, explained and educated the villagers who throw garbage and spit everywhere, guided the villagers to speak of civilization and built a clean and beautiful community home; Dedication, fraternity, mutual aid and progress----the young elderly regularly took care of the housework for the old, organized condolences to the old soldiers and seniors, carried forward the spirit of helping others, and strove to create an atmosphere of finding volunteers in difficulty and having time to be volunteers; Lecture on Family Women's Health Knowledge----In order to enhance health care awareness and enhance the ability to prevent and treat gynecological diseases, social workers and volunteers jointly organized this knowledge lecture.

These activities played the core leadership role of the rural elderly backbone volunteers, in particular, the old secretary and party members who have certain prestige in the local area, at the same time, have more network resources than others. They fully mobilized the enthusiasm of other volunteers, promoted the development of voluntary service, built self-confidence for the rural elderly and helped them integrate with the society.

\subsubsection{Summarizing and assessing}

Evaluation is very critical for the cultivation of volunteers, and it is mainly carried out from two aspects. One is process evaluation, which evaluates the process of cultivating elderly volunteers. Social workers participated in volunteer service activities in village $X$ together with volunteers. In the process of service, social workers gave the elderly the right to serve, led and guided them to learn volunteer service, stimulated the potential of volunteer service for the elderly, found out and gave full play to each individual's unique advantages. Social workers observe the performance of each volunteer, judged their mastery of volunteer service skills and service ability, and adjusted the cultivation strategy in real time according to the information feedback from process evaluation. The second is the effect evaluation. After holding lectures and carrying out activities, the senior volunteer team in Village X had basically formed and voluntary service had been successfully completed. The senior citizens who undertook the backbone of volunteers in voluntary service were pushing forward the development of various activities. They devoted themselves to voluntary service activities, expanded their knowledge of voluntary service, learned and mastered the methods of voluntary service, stimulated their potential, defined the direction of voluntary service, enhanced their spirit of voluntary service and improved the quality of voluntary service.

\section{RECOMMENDATIONS}

Voluntary service for the aged in rural areas should be actively integrated into the service for the aged in rural areas. We need to continuously improve and perfect the community volunteer service system for the aged. In addition, professional social workers should go deep into the countryside, combine and utilize the effective resources around them, contact the government and caring people, raise funds and manpower through multiple channels, and assist rural communities to build elderly service facilities. At the same time, we can actively carry 


\section{REFERENCES}

out voluntary service activities for the elderly in rural elderly left behind, combine theory with practice, and adjust measures to local conditions. We can register for volunteers on duty [6] and establish a standardized service system, use new media and other ways neatly to preach the spirit of volunteers in the elderly. Also, it is very important to give play to the leading role of prestigious and skilled elderly, and emphasize spiritual encouragement and affirmation [6]. We hope to develop the elderly volunteer service better in rural areas, and make the elderly volunteer service develop in a balanced way in urban and rural areas across the country.

\section{ACKNOWLEDGMENT}

This article is one of the phased achievements of the "13th Five-Year Plan" social science project of Jilin Provincial Department of Education, "Research on Synergy of Social Work and Community Governance in Jilin Province" (JJKH20170638SK) and the social science fund project of Jilin Province, "Research on Construction of Urban Community Space in the New Era" (2018B108).
[1] Qin Zhiying. Research on Diversification of Rural Endowment Service Providers in China [D]. Qinhuangdao: Yanshan University, 2015: 9-15.

[2] Wang Li. Social Work's Action Research in Fostering Rural Community Volunteers --Take a Voluntary Service Project of Caring Countryside Caretakers as an Example [D]. Lanzhou: Lanzhou University, 2016: 12-15.

[3] Wang Lijuan. Study on Participation of Young and Elderly Volunteers [D]. Shanghai: East China University of Technology, 2013: 4.

[4] Wu Cangping. "Doing something old" is an objective requirement for China to actively respond to the aging population $[\mathrm{J}]$. Population and Development, 2011 (6): 32-34.

[5] Gao Ying. Study on Long-term Mechanism Construction of Elderly Volunteers [D]. Shanghai: East China University of Political Science and Law, 2014: 16.

[6] Du Peng, Xie Lili, Li Yajuan. How to Expand Voluntary Service for the Elderly--An Empirical Study Based on Chaowai Street in Beijing [J]. Population and Development, 2015, 21 (1): 89-95. 